ORIGINAL ARTICLE

\title{
Factors Affecting Students Perception towards Faculty Evaluation of Teaching at Nowshera Medical College, Pakistan.
}

\author{
Sobia Haris ${ }^{1}$, Brekhna Jamil2 ${ }^{2}$ Muhammad Haris ${ }^{3}$, Farah Deeba ${ }^{4}$, Muhammad Jehangir Khan ${ }^{5}$, Imran Zaman Khan ${ }^{6}$
}

Article Citation: Haris S, Jamil B, Haris M, Deeba F, Khan MJ, Khan IZ. Factors Affecting Students Perception towards Faculty Evaluation of Teaching at Nowshera Medical College, Pakistan. Professional Med J 2022; 29(2):258-264. https://doi.org/10.29309/TPMJ/2022.29.02.6407

\begin{abstract}
Objective: To find out factors which are affecting student's perception towards teaching faculty evaluation. Study Design: Quantitative Cross-sectional Research. Setting: Nowshera Medical College, Nowshera. Period: March 2020. Material \& Methods: A pre-validated questionnaire of Student's evaluation of teaching instrument comprising 21 items, were administered. A total number of 208 students from different classes were agreed for participation. All participants were given equal preference. Data was entered in Excel sheet and analyzed through SPSS version 24. Results: It is evident that majority of students' i.e.51.27 \% had a positive perception towards the factors related to teachers in the student's evaluation of teaching Tool. Similarly, it has been depicted that majority of students i.e. $79.46 \%$ have shown highly positive significance towards the factors related to them in the instrument where as $40.6 \%$ has a positive perception towards the factors related to coursework. Conclusion: It was concluded that the faculty age, sex, qualification and medium of teaching are the major features which affect their evaluation by the students. Similarly, class size and students' grades were found to be major factors related to course and students in the tool. Thus, we conclude that overall perception of students towards Students evaluation of teaching was positive and highly significant.
\end{abstract}

Key words: $\quad$ Faculty Evaluation, Factors, Nowshera Medical College, Ratings, SET Tool, Student's Perception.

\section{INTRODUCTION}

Perception is the method that takes place within the individual which starts with the reception of excitatory stimulus till it is apprehended and understood by the person, so that the individual can distinguish oneself and the environment. ${ }^{1}$ Likewise, Jalaluddin Rahmat said that "one's insight on substances, proceedings or affairs is attained by supposing evidence and governing the message". ${ }^{1}$ Furthermore, assessment is a practical analytical method for gathering and making suggestion that ends in conclusions about the state of matters, worth, excellence, value, implication, or eminence of a program, invention, individual, strategy, suggestion or idea. ${ }^{2}$ While, teaching faculty assessment identify the level of faculty member accomplishments in the value of teaching and primes to impartiality in theoretical backgrounds. ${ }^{3}$ Similarly, Adams accept as true that faculty assessment is one of the key gauges of growth in the instructive system. Besides, in those institutes that assessment is regularly done, the eminence of teaching is enhanced. ${ }^{4}$ The assessment arrangement for faculty members in arena of medicine is of upheld significance for the reason that graduates are accountable for human well-being and life. ${ }^{5}$

Student's evaluation of teaching tool (SET) is broadly utilized in both North America and the UK as a resource of supporting and refining teaching eminence. ${ }^{6}$ SET is a current word that is utilized frequently with many preceding terms such as Student Evaluation of Educational Quality (SEEQ) and student's evaluation of teaching effectiveness etc. SET is broadly utilized in the assessment of faculty and their teaching usefulness. ${ }^{7,8}$ Erstwhile study on SET can be summed up in three groups: features of the course itself together with environmental aspects; features
1. BDS, MPH, MHPE (Scholar), Lecturer/Demonstrator, Department of Medical Education, Nowshera Medical College, Nowshera, Pakistan.

2. BDS, MPH, MHPE, PhD HPE (Scholar), Associate Professor, Institute of Health Professions Education \& Research, Khyber Medical University, Peshawar, Pakistan.

3. MBBS, MPhil, MPH, CHPE, CHR, PhD Anatomy (Scholar), Assistant Professor, Department of Anatomy, Nowshera Medical College, Nowshera, Pakistan.

4. BDS, MHR (Scholar), Lecturer/Demonstrator, Department of Medical Education, Nowshera Medical College, Nowshera, Pakistan

5. MBBS, FCPS (Pediatric Surgery), LLB, CHPE, Professor, Department of Pediatric Surgery, Makka Medical Center, Nowshera, Pakistan.

6. BDS, CHPE, MHPE (Scholar), Lecturer/Demonstrator, Department of Medical Education, Nowshera Medical College, Nowshera, Pakistan.

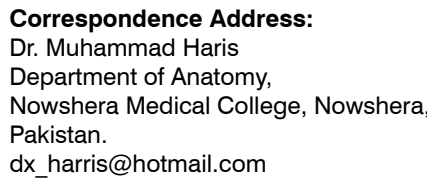


of the students themselves and their partialities in awareness and outlooks; and features of the teacher. ${ }^{9}$ Respondents are offered with evaluation proformas that enquire and score their insights of teachers and courses frequently on a 5-point Likert scale that ranges from strongly disagree to strongly agree. ${ }^{10}$

A study was done in Saudi Arabia in 2017 which also emphasized on identifying the reasons affecting student's thinking to SET. They found personality of the teacher as a biasing factor in evaluation of teachers. ${ }^{11}$ Educationists use SET to identify for faculty teaching activity and working. Moreover, a research in France (2017) presented that gender disturb the student's assessment of instruction. Female instructors get less SET score, regardless of indication that female instructor's areas competent instructors as their male counterparts. ${ }^{12}$ However, some of researchers have identified that it does not work properly about assessment of teacher's activity. ${ }^{13}$ But there are certain researches which have publicized that it is effective and dependable instrument. ${ }^{14,15}$ Annan et al. appraisal of the study showed that the greater the class proportions, the lesser the respondent scores. ${ }^{16}$ According to a research done in 2011, top graduate educational institutes did the assessment system by means of the student and administrator grading methodology by both students and administrators. ${ }^{17}$

Moreover, Pakistan is also among those nations, which identified the necessity to assess and develop the teaching faculty of all teaching institutions. One of research done in Multan in 2017 is grounded on ideas that include cognitive dissonance theory, together with students' assessment of faculty and courses they teach. Likewise, it was also found that students ratings of teachers differ with respect to their grades. ${ }^{18}$ Another study was done in Peshawar showed vital differences between students and teachers in relation of several facets of SET development. Generally, teaching faculty seems to be bearing in mind that the students are non-serious about SET method. Results recommended that students are more anxious about the deficiency of SET ideas in decision making. ${ }^{19}$
Furthermore, teaching faculty evaluation was started in the month of October, 2019 in Nowshera Medical College. In this year, first 4 batches were enrolled in our Medical College. However, after analyzing student's evaluation proformas, the Department of Medical Education came across decision that there are some factors which are affecting the evaluation. So, it was decided to conduct this study in Nowshera Medical College by using SET questionnaire to identify those factors which affect student's perception towards faculty teaching evaluation, as to our knowledge, literature related to such study in Pakistan has been deficient.

\section{MATERIAL \& METHODS}

A quantitative cross-sectional study was utilized in the month of March, 2020 to find the substantial association on students' perception and other demographic aspects. A total number of 208 students from different classes were agreed for participation. All participants were given equal preference. A pre-validated questionnaire was used. Moreover, ethical endorsement was attained from the Ethical Board vide letter No: 143-47/NMC/ ERB dated: 06/03/2020. However, the sample was chosen randomly, the students' readiness to take part in the study was also kept in consideration in demand to achieve more precise outcomes. In the meantime, the sample was carefully chosen through approachability, the instrument was directed self-sufficiently. Prior informed consent was attained from all the contestants and they were assured of confidentiality. For this, students were demanded to drop the filled-up forms in a sealed case in order to ensure anonymity. The demographic data of the sample is shown in the following table, which was analyzed through SPSS version 24 .

A pre-validated questionnaire of SET instrument comprising 21 items, were administered. Each item in SET was rated on Likert scale (1-5). Social and demographic particulars of the students i.e. year of medical school, gender and age were also mentioned. 


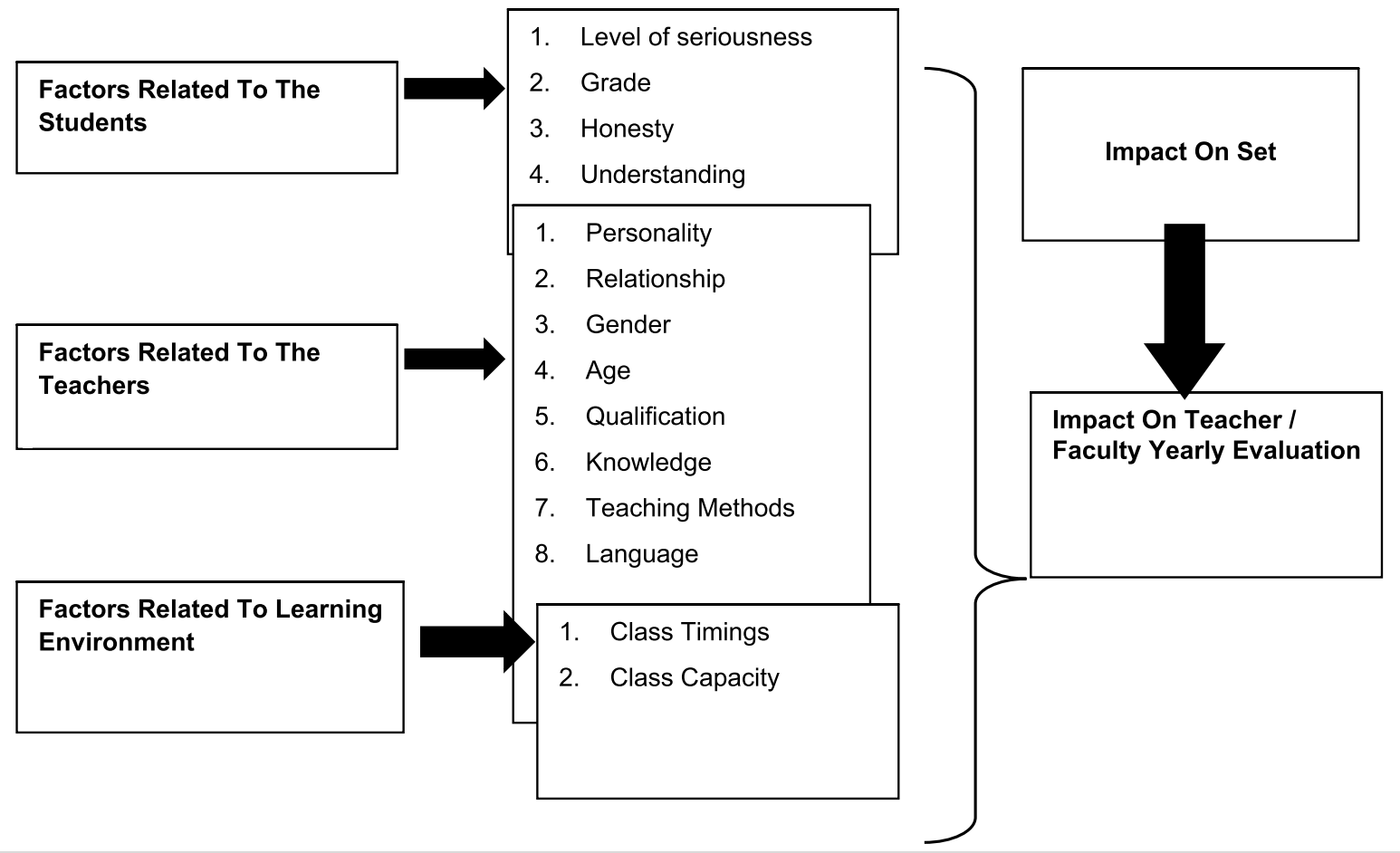

Figure-1. Conceptual framework of SET tool.

\section{Sample Selection}

\section{Inclusion Criteria}

Those students of the Nowshera Medical College who are enrolled in it and want to participate.

\section{Exclusion Criteria}

Those students who do not want to participate due to unknown reasons. Similarly, all those students who did not fill the questionnaire completely were excluded from the study. Moreover, migrated students from other colleges to Nowshera Medical College during their medical education were also excluded.

\begin{tabular}{|l|c|c|}
\hline \multicolumn{1}{|c|}{ Gender } & Frequency & Percent \\
\hline Male & 118 & 56.7 \\
\hline Female & 90 & 43.3 \\
\hline Age Group & & \\
\hline $18-20$ & 91 & 43.8 \\
\hline $21-23$ & 97 & 46.6 \\
\hline $24-26$ & 20 & 9.6 \\
\hline Medical School Year & & \\
\hline First Year & 51 & 24.5 \\
\hline Second Year & 53 & 25.5 \\
\hline Third Year & 53 & 25.5 \\
\hline Fourth Year & 51 & 24.5 \\
\hline
\end{tabular}

Table-I. Percentage distribution of the sample according to gender, age, year of study.
Out of 208 students, more than half $(56.7 \%)$ were male students, and only $43.3 \%$ were female. Similarly, $43.8 \%$ were in the age group of $18-20$ years while $46.6 \%$ were in $21-23$ years and $9.6 \%$ were in 24-26-year age group.

\section{Data Analysis and Findings}

Statistical method i.e., frequency was checked for each factor and percentages were checked for each statement which are as follows;

It is evident from the Table-Il that almost 15.98\% of the students strongly disagreed whereas $14.98 \%$ disagreed to the SET tool. In total, $30.96 \%$ of students disagreed and thus had a negative perception towards the factors related to teachers in SET tool. Similarly, $26.04 \%$ agreed and $25.23 \%$ strongly agreed to the factors related in SET tool and thus in toting, $51.27 \%$ had a positive perception towards the factors related to teachers in SET tool. However, $17.8 \%$ had a neutral approach towards the factors related to teachers in SET tool.

It has been depicted in the Table-III that almost $4.65 \%$ of the students strongly disagreed and $5.21 \%$ agreed to the factors related to themselves 
in SET tool. In total, $9.86 \%$ of students had a negative perception towards the factors related to them in SET tool. Similarly, $43.33 \%$ strongly agreed and $36.13 \%$ agreed to the factors related to the students in SET tool. Thus in totaling, $79.46 \%$ had a positive perception towards themselves in SET tool. However, $10.65 \%$ had a neutral approach towards the factors related to them in SET tool.

In the same way, Table-IV shows that almost
$16.35 \%$ strongly disagreed whereas $20.45 \%$ disagreed to the factors related to course and thus almost $36.8 \%$ of students had a negative perception towards the factors related to coursework in SET tool. Similarly, 14.65\% strongly agreed and $25.95 \%$ agreed to the factors related to course and thus in total almost $40.6 \%$ had a positive perception towards the factors related to coursework. However, $22.6 \%$ had a neutral approach towards the factors related to coursework in SET tool.

\begin{tabular}{|c|c|c|c|c|c|c|}
\hline S. No & Statement & SD \% & D \% & NS $\%$ & A \% & SA $\%$ \\
\hline 1 & $\begin{array}{l}\text { By evaluating my teachers/faculty, I am actually helping them } \\
\text { improve their teaching effectiveness }\end{array}$ & 6.3 & 4.8 & 14.4 & 38.5 & 36.1 \\
\hline 2 & $\begin{array}{l}\text { Teachers/faculty change their teaching methods as a result of } \\
\text { student evaluations }\end{array}$ & 11.5 & 15.4 & 31.3 & 29.3 & 12.5 \\
\hline 3 & I am comfortable taking courses with female teachers/faculty & 6.3 & 12.5 & 13.9 & 23.6 & 43.8 \\
\hline 4 & I am comfortable taking courses with male teachers/faculty & 7.2 & 3.4 & 13.5 & 35.6 & 40.4 \\
\hline 5 & I am more comfortable with English-speaking teachers/faculty & 9.1 & 9.1 & 24.0 & 28.4 & 29.3 \\
\hline 6 & $\begin{array}{l}\text { I am more comfortable with Non-English-speaking teachers/ } \\
\text { faculty }\end{array}$ & 12.5 & 11.1 & 22.1 & 29.8 & 24.5 \\
\hline 7 & $\begin{array}{l}\text { When evaluating my Teachers/faculty, I usually pay more } \\
\text { attention to their personality (i.e., friendless, leniency, looks, } \\
\text { dress, etc.) }\end{array}$ & 23.6 & 20.2 & 15.9 & 19.7 & 20.7 \\
\hline 8 & $\begin{array}{l}\text { If I have a good relationship with my teachers/faculty, I will rank } \\
\text { him/her high on teaching effectiveness }\end{array}$ & 28.4 & 27.4 & 15.9 & 18.8 & 9.6 \\
\hline 9 & $\begin{array}{l}\text { I prefer taking courses with young and enthusiastic teachers/ } \\
\text { faculty }\end{array}$ & 3.4 & 5.8 & 13.5 & 31.3 & 46.2 \\
\hline 10 & $\begin{array}{l}\text { I prefer taking courses with older and experienced teachers/ } \\
\text { faculty }\end{array}$ & 11.5 & 7.7 & 25.5 & 29.3 & 26.0 \\
\hline 11 & $\begin{array}{l}\text { If I ask my Teachers/faculty a question that is related to the } \\
\text { subject being taught and my teachers responds by saying "I am } \\
\text { not really sure, but I will check on that and get back to you," I } \\
\text { will still not consider him or her knowledgeable }\end{array}$ & 29.8 & 31.7 & 14.4 & 12.0 & 12.0 \\
\hline 12 & $\begin{array}{l}\text { If I have a spoiled relationship with my teachers/faculty, I will } \\
\text { rank him or her low on teaching effectiveness }\end{array}$ & 44.7 & 26.0 & 11.1 & 7.7 & 10.6 \\
\hline 13 & $\begin{array}{l}\text { The qualification of my teachers/faculty affects my evaluation } \\
\text { rating on my teachers }\end{array}$ & 13.5 & 19.7 & 15.9 & 34.6 & 16.3 \\
\hline \multirow{2}{*}{\multicolumn{7}{|c|}{$\begin{array}{l}\text { quency: } \\
\text { Table-II. Factors related to the teachers. }\end{array}$}} \\
\hline & & & & & & \\
\hline S. No & Statements & SD \% & D \% & NS $\%$ & A \% & SA $\%$ \\
\hline 1 & NMC students should take faculty evaluations seriously & 4.3 & 2.9 & 9.1 & 37.0 & 46.6 \\
\hline 2 & $\begin{array}{l}\text { I fill out all the questions including recommendations and } \\
\text { suggestions }\end{array}$ & 4.8 & 3.4 & 7.7 & 47.6 & 36.5 \\
\hline 3 & I read and understand each statement before I rate it & 2.9 & 1.0 & 5.8 & 37.5 & 52.9 \\
\hline 4 & $\begin{array}{l}\text { My rating of my teachers/faculty is affected by my expected } \\
\text { grade in the course }\end{array}$ & 13.5 & 20.2 & 23.1 & 27.4 & 15.9 \\
\hline 5 & $\begin{array}{l}\text { My responses are always honest while evaluating my } \\
\text { teachers/faculty }\end{array}$ & 1.0 & 1.9 & 3.8 & 29.3 & 63.9 \\
\hline 6 & $\begin{array}{l}\text { I always understand the seriousness of the students } \\
\text { Evaluation of teaching process }\end{array}$ & 1.4 & 1.9 & 14.4 & 38.0 & 44.2 \\
\hline \multicolumn{2}{|r|}{ Net Frequency: } & 4.65 & 5.21 & 10.65 & 36.13 & 43.33 \\
\hline
\end{tabular}

Table-III. Factors related to the students. 


\begin{tabular}{|c|l|c|c|c|c|c|}
\hline S. No & Statements & SD \% & D \% & NS \% & A \% & SA \% \\
\hline $\mathbf{1}$ & The class timings of our lecturer affect my evaluation ratings & 11.1 & 17.8 & 22.6 & 29.3 & 19.2 \\
\hline $\mathbf{2}$ & $\begin{array}{l}\text { The class capacity (more or less number of students in the } \\
\text { class) affects my evaluation rating on teachers/faculty }\end{array}$ & 21.6 & 23.1 & 22.6 & 22.6 & 10.1 \\
\hline & Net Frequency & 16.35 & 20.45 & 22.6 & 25.95 & 14.65 \\
\hline
\end{tabular}

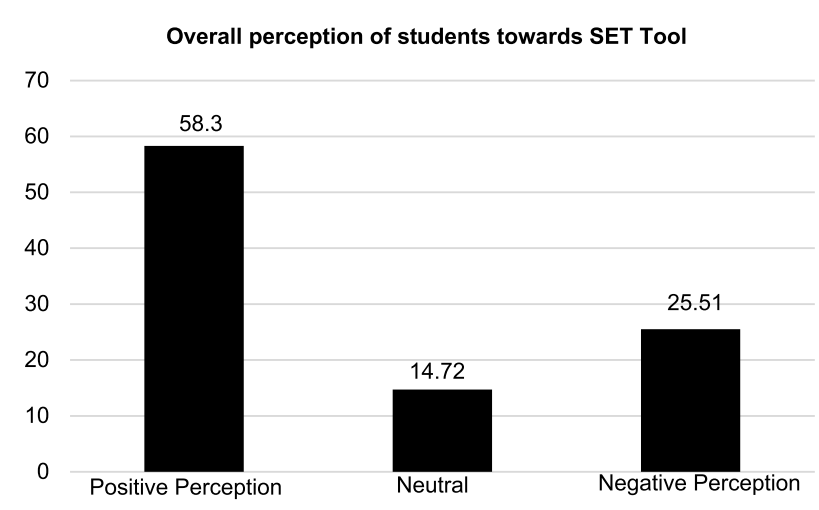

Figure-2. Graph showing overall perception of the students towards the SET tool.

The overall perception of the students regarding the SET tool was positive (58.3\%) as shown in Figure-2 However, 14.72\% (Figure-2) had a neutral response towards it. While, the negative perception was $25.51 \%$.

\section{DISCUSSION}

Assessment of instruction processes emphasizes on several perspectives of schooling, casing arenas such as forecasting and training of the class, information of the topic, the tutorial surroundings, and teaching of ideas. These add up to the precise set of courses. On the contrary hand, sides such as significance to central part standards, emotional response of the instructors to pupils, and activities headed for scholars comprise the implicit syllabus. The most important rationale of SET is to assist the teaching staff to recognize the pros and cons of their instruction and assessment ways. ${ }^{20-22}$ It was observed in the present study that in the factors pertaining to teachers, students show highly significant response towards teaching effectiveness. As shown in table $2,74.6 \%$ of students were in favor of the factor that they are helping their teachers to improve their teaching effectiveness through SET evaluation which is in line with the study conducted in Belgium (2017). Similarly, 41.8\% of students were of the opinion that the evaluation of teachers done by them actually positively affects the teaching methodology of their teachers. ${ }^{7,8}$ Out of the evaluation, $76 \%$ of the students were easy with their male teachers where as they were less easy with their female teachers which shows similar trend with the studies done. ${ }^{12,23}$

Moreover, participants of the present study were also in favor with item no 5 showing high significance with English language (57.7\%). Similar study was done in American University of Sharjah (UAE), which also determine the degree to which SET is influenced by language factor. ${ }^{24}$ Likewise, another biasing factor pointed out from results was age of the teaching faculty, as $77.5 \%$ of students were agreed to the extent that they prefer to take courses from young teachers as compared to old faculty which showed a trend towards positive perception by the students. However, they rated the old faculty less as compared to the young faculty for teaching which $55.3 \%$ was. Furthermore, age of the teachers was also found as a biasing factor in a study conducted which also depicted that young teachers receive high ranking than older teachers. ${ }^{25}$ Similarly, qualification of teachers was also a biasing factor in factors pertaining to teachers as Table-II shows, that $50.9 \%$ of students agreed that the qualification of their teachers influence their evaluation. Factors related to the course evaluation of class timings are an influencing factor. Here results show that $48.5 \%$ of the students concluded that class timings affect their teaching evaluation rating which coincide with findings of another study done in $1986 .^{15,26}$

Moreover, students related factors include grade as a prompting factor. Almost $43.4 \%$ of the students showed a positive trend and agreed to the fact that the evaluation of their teacher's teaching is affected by their expected grades. Similar trend was also showed in study conducted in $\mathrm{Abu}$ Dhabi and Multan. ${ }^{15,18}$ Significant findings from 
students' feedback were also noted from another study which depicted that $80 \%$ of faculty had a median score of $>4$ in unequivocal program of study, representing that a good number of the students approved that the faculty instruct their foundation area under discussion very well. On the other hand, only $20 \%$ of faculty had a median score $>4$ in contained set of courses. Faculty, in their opinion, completely established that pupils be thought to be concerned in the assessment of faculty and that student response ensures on the whole faculty improvement in the college and can be used as a instrument for quality assurance in medical education. ${ }^{24}$ SETs will probably stay one of the most important assessment paraphernalia of instruction efficaciously in medical and health teaching for the anticipated upcoming. The aforesaid effectiveness of the consequences on teachers work will as well probably stay momentous. Considerations ought to be comprehended vis-à-vis the consistency and legitimacy of SETs, chiefly at those schools or collages that make use of home-based systems. ${ }^{27}$

\section{CONCLUSION}

Keeping in view the above aforementioned results, it was concluded that the tutor's age, sex, qualification and medium of teaching are the major aspects which affect their evaluation by the students. The directly above outcomes are in association with numerous other study papers, which have proved that the results of the present study are accurate. Similarly, class size and students' grades were found to be major factors related to course in SET tool. It also came out from the results that the rating of teacher's evaluation floats with the student's grades. For example, it was found agreed that there is a direct link between the expectation of a high grade with high rating, and the expectation of a low grade with low rating. Thus, we conclude that general insight of students to SET tool was positive and highly significant.

\section{LIMITATIONS AND RECOMMENDATIONS}

In the present study, duration for collecting data was limited. Moreover, students were not interested to participate in the study whole heartedly. Keeping in view the aforementioned limitations, we would recommend that future studies of the same nature should be conducted in multiple centers with bigger sample size and involvement of other professions students.

Copyright $(11$ June, 2021.

\section{REFERENCES}

1. Haqza, V. (2014). The correlation between students' perception of classroom environment and motivation in learning English at the second year of Ma Darel Hikmah Pekanbaru (Doctoral dissertation, Universitas Islam Negeri Sultan Syarif Kasim Riau).

2. Mertens, D. M., \& Wilson, A. T. (2018). Program evaluation theory and practice. Guilford Publications.

3. Seif, A. A. (2004). Educational measurement, assessment and evaluation. Tehran: Doran Publications, 128.

4. Akbari M, Moeintaghavi A, Ghanbari $\mathrm{H}$, Bageri M, Otoufi A. A Comparison of the Students' and Teachers' Viewpoints about the characteristics of a good teacher in dentistry. Journal of Mashhad Dental School. 2014; 38(4):281-90.

5. Sharifinia H, Ebadi A, Hekmat Afshar M. The characteristics of good teacher based on view points of students and teachers: A qualitative study. Quarterly Journal of Health Breeze. 2014 Dec 1; 2(1):10 .

6. Hammonds, F., Mariano, G. J., Ammons, G., \& Chambers, S. Student evaluations of teaching: Improving teaching quality in higher education. Perspectives: Policy and Practice in Higher Education, 2017; 21(1), 26-33. https://doi.org/10.1080/13603108.2016.1227388

7. Spooren P, Christiaens W. I liked your course because I believe in (the power of) student evaluations of teaching (SET). Students' perceptions of a teaching evaluation process and their relationships with SET scores. Studies in educational evaluation. 2017 Sep 1; 54:43-9.

8. Spooren $\mathrm{P}$, Vandermoere $\mathrm{F}$, Vanderstraeten $\mathrm{R}$, Pepermans K. Exploring high impact scholarship in research on student's evaluation of teaching (SET). Educational Research Review. 2017 Nov 1; 22:129-41.

9. Worthington AC. The impact of student perceptions and characteristics on teaching evaluations: A case study in finance education. Assessment \& Evaluation in Higher Education. 2002 Jan 1; 27(1):49-64. 
10. Spooren P, Brockx B, Mortelmans D. On the validity of student evaluation of teaching: The state of the art. Review of Educational Research. 2013 Dec; 83(4):598642.

11. Mohammed TA, Pandhiani SM. Analysis of factors affecting student evaluation of teaching effectiveness in Saudi higher education: The case of Jubail University college. American Journal of Educational Research. 2017; 5(5):464-75.

12. Anne B. Gender biases in student evaluations of teachers. Journal of Public Economics. 2017; 145:2741.

13. Hornstein HA. Student evaluations of teaching are an inadequate assessment tool for evaluating faculty performance. Cogent Education. 2017 Jan 1; 4(1):1304016.

14. Gupta P, Bajaj N. Perceptions of the students and faculty of a dental college towards student evaluation of teaching (SET): A cross-sectional study. Cureus. 2018 Mar; 10(3).

15. Dev SS, Qayyum N. Major factors affecting students' perception towards faculty evaluation of teaching (SET). Journal of Social Studies Education Research. 2017 Oct 2; 8(3):149-67.

16. Annan SL, Tratnack S, Rubenstein C, Metzler-Sawin E, Hulton L. An integrative review of student evaluations of teaching: Implications for evaluation of nursing faculty. Journal of Professional Nursing. 2013 Sep 1; 29(5):e10-24.

17. Kamali F, Yamani N, Changiz T. Investigating the faculty evaluation system in Iranian Medical Universities. Journal of education and health promotion. 2014;3.

18. Sarwar M, Dildar M, Shah AA, Hussain S. Relationship among students' academic achievement, students' evaluation of teacher and students' evaluation of course. Dialogue. 2017 Mar 31; 12(1):50.
19. Siddique M, Said N, Butt M. Perspectives of students' and faculty on student evaluation of teaching at institute of management sciences Peshawar. Perspectives. 2019 Dec 1; 13(3):65-78.

20. Lata H, Walia L, Gupta V. Student feedback on teaching and evaluation methodology in physiology. Southeast Asian J Med Educ. 2008; 2:31-7. [Google Scholar].

21. Richardson BK. Feedback. Acad Emerg Med. 2004; 11:e1-5. [PubMed] [Google Scholar].

22. Biggs J. Teaching for quality learning at University. 2nd ed. Buckingham: SRHE/Open University Press; 2003. [Google Scholar].

23. Morgan HK, Purkiss JA, Porter AC, Lypson ML, Santen SA, Christner JG, Grum CM, Hammoud MM. Student evaluation of faculty physicians: Gender differences in teaching evaluations. Journal of Women's Health. 2016 May 1; 25(5):453-6.

24. Al-Issa A, Sulieman $H$. Student evaluations of teaching: Perceptions and biasing factors. Quality Assurance in Education. 2007 Jul 17.

25. Goebel BL, Cashen VM. Age, sex, and attractiveness as factors in student ratings of teachers: A developmental study. Journal of Educational Psychology. 1979 Oct; 71(5):646.

26. Cranton PA, Smith RA. A new look at the effect of course characteristics on student ratings of instruction. American Educational Research Journal. 1986 Mar; 23(1):117-28.

27. Nemec II EC, Baker DM, Zhang D, Dintzner M. Development of valid and reliable tools for student evaluation of teaching. Currents in Pharmacy Teaching and Learning. 2018 May 1; 10(5):549-57.

\section{AUTHORSHIP AND CONTRIBUTION DECLARATION}

\begin{tabular}{|c|c|c|c|}
\hline No. & Author(s) Full Name & Contribution to the paper & Author(s) Signature \\
\hline 1 & $\begin{array}{l}\text { Sobia Haris } \\
\text { Brekhna Jamil }\end{array}$ & $\begin{array}{l}\text { Overall conduction of research } \\
\text { and analysis of results. } \\
\text { Data Analysis. }\end{array}$ & \\
\hline 3 & Muhammad Haris & $\begin{array}{l}\text { Overall designing of the study, } \\
\text { critical appraisal and data analysis. }\end{array}$ & \\
\hline 4 & Farah Deeba & Introduction Writing. & \\
\hline 5 & Muhammad Jehangir Khan & $\begin{array}{l}\text { Referencing and complication } \\
\text { of the whole draft. }\end{array}$ & \\
\hline 6 & Imran Zaman Khan & Discussion Writing. & 22 \\
\hline
\end{tabular}

